\title{
Hemicellulose-Based Hydrogels Present Status and Application Prospects: A Brief Review
}

\author{
Lisong Hu, Menghao Du, Jinping Zhang \\ Research Institute of Subtropical Forestry Chinese Academy of Forestry, Fuyang, China \\ Email: lisohu@hotmail.com
}

How to cite this paper: $\mathrm{Hu}, \mathrm{L}$. S., $\mathrm{Du}, \mathrm{M}$. H., \& Zhang, J. P. (2018). Hemicellulose-Based Hydrogels Present Status and Application Prospects: A Brief Review. Open Journal of Forestry, 8, 15-28. https://doi.org/10.4236/ojf.2018.81002

Received: November 9, 2017

Accepted: November 27, 2017

Published: November 30, 2017

Copyright $\odot 2018$ by authors and Scientific Research Publishing Inc. This work is licensed under the Creative Commons Attribution International License (CC BY 4.0).

http://creativecommons.org/licenses/by/4.0/

\begin{abstract}
Hemicellulose is one of the most abundant natural resources, which extensively exist in the pant tissues as the compositions of the cell wall filling between lignin and cellulose. In this review, the hemicellulose based hydrogels was illustrated in details including the hemicellulose derivatives (such as precursor of hemicellulose based hydrogel), hydrogels fabrication methods, origin of hemicellulose, composite hydrogels, and so on. In addition, the authors as well overviewed the new methods for fabrication of hemicellulose based hydrogels and special functional hemicellulose based hydrogels.
\end{abstract}

\section{Keywords}

Hemicellulose, Hydrogels, Graft polymers, Swelling, Conductivity

\section{Introduction}

Hydrogels are the mainly three-dimensional, cross-linked networks (forming by chemical and physical method) of hydrophilic polymers that have ability of adsorbing up to thousands of times of their dry weight in water (Ahmed, 2015; Seliktar, 2012). Hydrogels have many excellent properties and extensive applications such as hydrophilicity, soft tissue-mimicking consistency, high permeability to metabolites, oxygen resilience and environmental sensitivity (Yamato, Konno, Utsumi, Kikuchi, \& Okano, 2002). Hydrogels are wide applied in medical fields such as soft contact lenses (Katsoulos, Karageorgiadis, Vasileiou, Mousafeiropoulos, \& Asimellis, 2009; Yasuda, 2006), tissue engineering (Ma, Tang, Billingham, Armes, \& Lewis, 2003; Matricardi, Di Meo, Coviello, Hennink, \& Alhaique, 2013), drug delivery (Noro, Hayashi, \& Matsushita, 2012), wound dressing (Ferreira et al., 2009; Melandri et al., 2006), biosensor (Beines, Klosterkamp, Menges, Jonas, \& Knoll, 2007), biomimetic mineralization (Huang et al., 2013), and cancer therapy (Zhang, Mardyani, Chan, \& Kumacheva, 2006). 
Natural hydrogels such as starch, chitin, cellulose and alginic acid were gradually replaced by synthetic hydrogels which have long service life, high capacity of water absorption, and high gel strength, during last two decades. Synthetic polymers usually have well-defined structures that can be modified to yield tailorable degradability and functionality (Jagur-Grodzinski, 2009).

Due to the advantage of hydrophilicity, structural versatility, nontoxicity, and broad potential of chemical modification, polysaccharides are highly interesting in the design of hydrogels. Various polysaccharides have been investigated for hydrogel formulations including alginate, dextran, chitosan, starch, and purified hemicellulose (Chang, Duan, \& Zhang, 2009; Chen, Jo, \& Park, 1995; Hennink, Franssen, van Dijk-Wolthuis, \& Talsma, 1997). In the agricultural field, release systems for fertilizers are a long-known opportunity to reduce costs and environmental impact as well as increase the profit. Another possible use for release systems in agriculture is a seed treatment that enables so-called relay cropping or cover crops to increase crop yields per area and year as well as protect the land against erosion.

\section{Hemicellulose}

Hemicellulose as natural polysaccharide is the second most abundant component of the plant materials. Plant materials main consist of cellulose, hemicellulose and lignin. Hemicellulose is about $20 \%-30 \%$ of the total weight of the lignocellulosic biomass (Anwar, Gulfraz, \& Irshad, 2014). Unlike cellulose, hemicellulose consists of shorter chains 500 - 3000 sugar units as opposed to 7000 - 15,000 glucose molecules per polymer.

\section{Structure of Hemicellulose}

Hemicellulose is hetero polymers (matrix polysaccharides) constructed by different polysaccharides with different chemical linkages. Hemicellulose has a random, amorphous structure with little strength. The main unit of the polysaccharides is pentose and hexose. The unit of the pentose and hexose are xylose, mannose, galactose, rhamnose, and arabinose as shown in Figure 1.

Different hemicellulose compositions, structures and amounts could be obtained from different source of different biomass. For example, the main hemicellulose in hardwood is O-acetyl-(4-O-methylglucurono) xylan (Figure 2). In the backbone of the hardwood, approximately $10 \%$ of xylopyranose are substituted by 4-o-methyl glucuronic acid.

In contrast, the predominant component of softwood hemicellulose is O-acetyl-galactoglucomannan (AcGGM) (Figure 3). The backbones of softwood hemicellulose are composed by mannose units combining with glucose units randomly (Ayoub, Venditti, Pawlak, Sadeghifar, \& Salam, 2013; De \& Visser, 2001).

There are several methods applied to separate the hemicellulose from the wood materials such as acid pretreatments (Nguyen, Tucker, Keller, \& Eddy, 


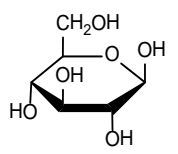

$\beta$-D-Glcp

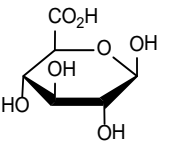

$\beta$-D-Glc $c_{p} \mathrm{U}$

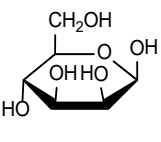

$\beta-\mathrm{D}-\mathrm{Man}_{p}$

Hexoses

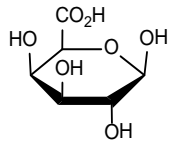

$\beta-\mathrm{D}-\mathrm{Gal}_{p} \mathrm{U}$

Hexuronics
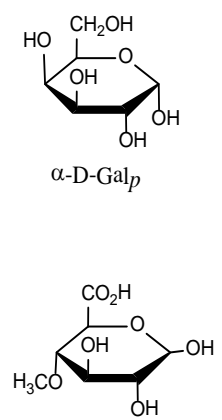

4-O-Me- $\alpha, \beta-\mathrm{D}-\mathrm{Glc} p \mathrm{U}$

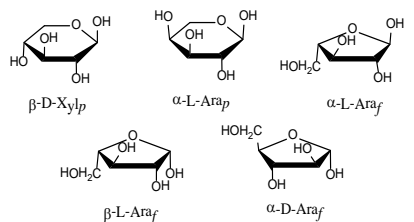

Pentose

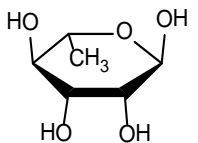

$\alpha$-L-Rhap

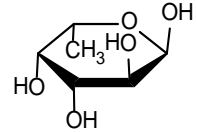

$\alpha-\mathrm{L}-\mathrm{Fac}_{p}$

Deoxyhexoses

Figure 1. Main monomeric sugars of hemicelluloses.

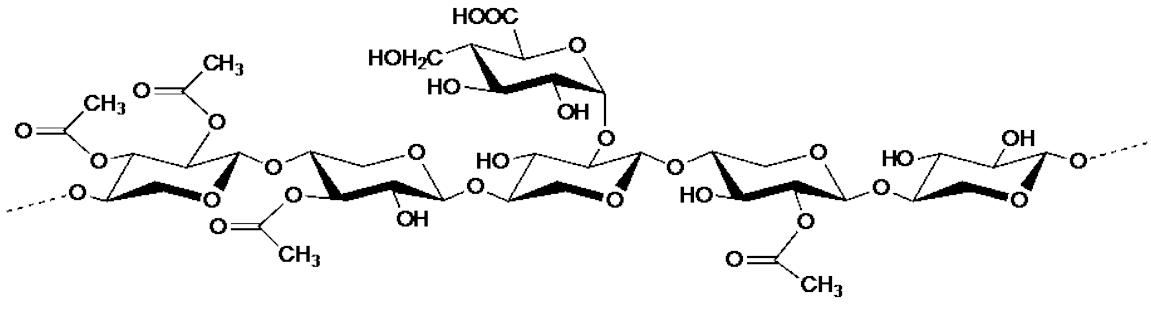

Figure 2. Main hemicellulose of hardwoods: O-acetyl-4-o-methylgucoronoxylan.

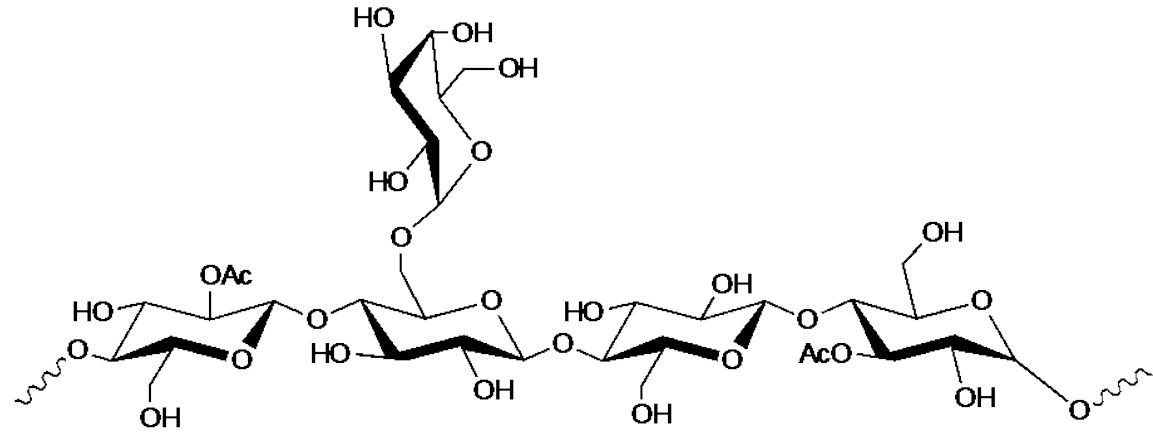

Figure 3. Main hemicellulose of softwoods: O-acetyl-galactoglucomannan (AcGGM).

2000), alkaline extraction (Egüés, Sanchez, Mondragon, \& Labidi, 2012), liquid hot-water extraction (Hasegawa, Tabata, Okuma, \& Mae, 2004), steam treatment (Palm \& Zacchi, 2003), ionic liquid extraction (Froschauer et al., 2013) and so on. These methods are available to extract the hemicellulose. However, acid pretreatment such as sulfuric acid, could obtain more degraded products dissolved sugars. While hot-water method could cleave the acetate group from hemicellulose, Ionic liquid method has been used by Froschauer and coworkers to obtain the hemicellulose with high purity. Alkaline method is extensively applied and well-studied in extract hemicellulose. The reason is that alkaline method could furthest retain integrity of hemicellulose the different method employed denpends on what the product you target to. As for the hydrogel and film, it may be extremely important to use alkaline method for the separation of hemicellulose from biomass. 


\section{Hemicellulose Based Hydrogels}

Hemicellulose is one of the most abundant natural resource, which are extensively exist in the plant tissue as the compositions of the cell wall filling between lignin and cellulose, with the chemical bond that hemicellulose is combined with lignin and through van der's force bind with cellulose. Hemicelluloses have tremendous potential in various fields. Due to their special properties, unique structure with huge amount of hydroxyl group, which could be modified by many kinds of reactions such as ether, ester, chemical crosslinking, hemicellulose tends to be modified by chemical reactions and physical interactions to manufacture lots of products such as packing films, oxygen barrier and water-resistant coatings (Van Tuil, Fowler, Lawther, \& Weber, 2000). Many kinds of hemicellulose from different of plants are applied to preparation of hydrogel, such as birch wood, aspen wood, spruce, bamboo, straw and so on.

\subsection{Hemicellulose Derivatives}

Several monomers have been used to prepare hemicellulose based hydrogels. These monomers include acrylic acid (AA), maleic acid, methacrylic acid and others. Acrylic acid is an important monomer which is widely used for the preparation of functional hydrogels. Acrylic acid as monomer is well studied and known as a very effective monomer for forming hydrogel. Indeed, acrylic acid can easily react with hemicellulose extracting from most kinds of plants. In research by Peng and coworkers, hemicellulose which was extracted from bamboo by using alkali method $(10 \% \mathrm{KOH})$ in the presence of cross-linker copolymerized with acrylic acid as shown in (Figure 4). Different ratio of $\mathrm{MBA} / \mathrm{XH}$ and $\mathrm{AA} / \mathrm{XH}$ were employed to investigate the influence of the networks. The results showed as-prepared hydrogels can absorb 91 to 822 times weight of itself, and were sensitive to ph. The hydrogels also have the feature of reversible on-off switching behavior in acidic-basic solutions or water-ethanol or acetone solution (Peng, Ren, Zhong, Peng, \& Sun, 2011). In another study, the hydrogel by grafting acrylic acid on the backbone of hemicellulose possessed honeycomb-like porous structure and had remarkable pH-sensitivity. Meanwhile, the biodegrade ability was conducted as well. In fact, the hydrogel can be degraded, due to their hemicellulose ingredients (Sun, Wang, Jing, \& Mohanathas, 2013).

Hemicellulose esterification with maleic anhydride in DMSO was performed by Voepel et al. (Voepel et al., 2009). In this study, hemicellulose separated from pulp of spruce grafted with maleic acid to produce the matrix of ionic hydrogel. The hemicellulose derivatives were applied to forming hydrogel by redox initiative system, and the ratio of swelling, mechanical properties were investigated. The drug release experiments were carried out by using caffeine and vitasyn blue as model drugs. The results showed different types of hydrogel had different release rate of drugs, the fast time of $50 \%$ of caffeine was $13 \mathrm{~min}$, and $50 \mathrm{~min}$ as for the vitasyn blue. However, the maleic acid added to AcGGM, the released time will slower than the any of the single kind of as-prepared hydrogel. Another study 


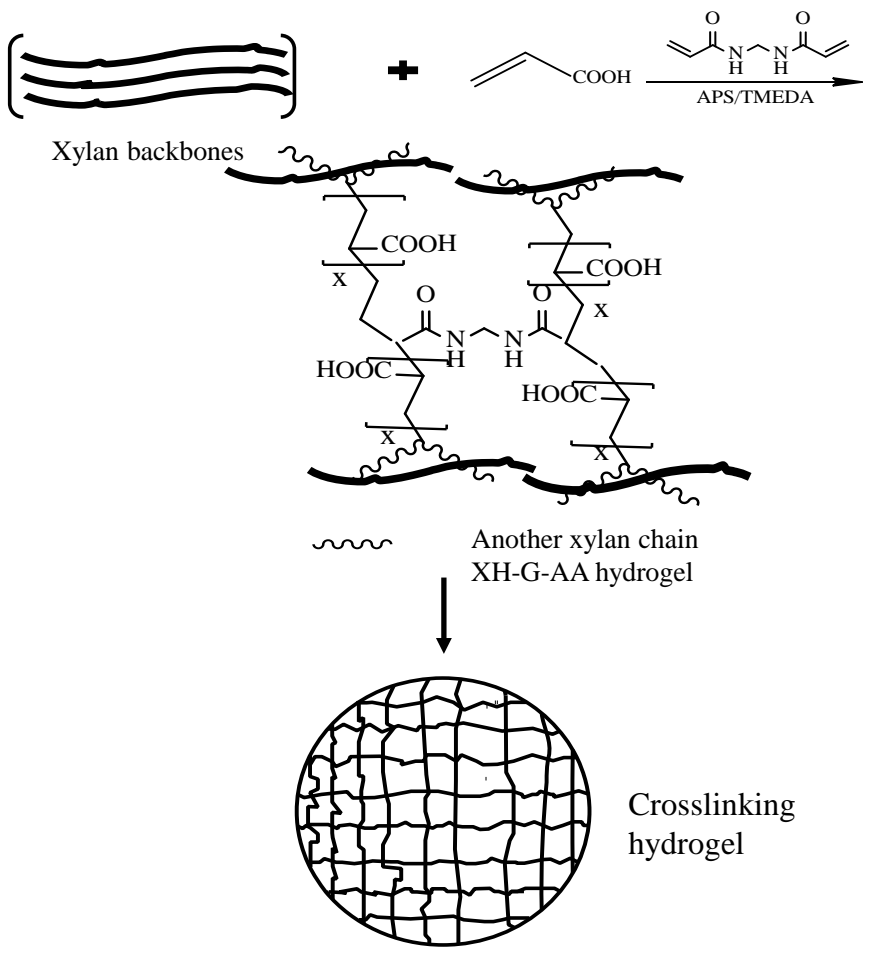

Figure 4. Preparation of xylan-rich hemicellulose based hydrogels with acrylic acid (Peng et al., 2011).

by Maleki and coworkers developed full interpenetrating polymer network (IPN) by using a couple of precursors (Maleki, Edlund, \& Albertsson, 2017). The shear storage modulus of IPNs was 2.5 - 5 times higher than that of the corresponding precursor single network. The swelling rate were faster compared the single network gels.

\subsection{Synthesis of Methacrylic Hydrogels}

Acrylic acid is frequently grafted molecular for preparing hemicellulose-based hydrogel, due to its excellent reaction activity. Researchers studied also studied its analogous such as methacrylic acid to prepare hydrogel. Ferrari and coworkers designed renewable hemicellulose based amidoamine hydrogels that prepared through free radical copolymeriaztion of poly (amidoamine) and hemicellulose derivatives. In research, the synthetic approach was viable in order to fabricate the functional hydrogels. The results indicated that as-prepared hydrogels displayed significant high adsorption capacity for heavy metal ions such as $\mathrm{Cu}^{2+}$, $\mathrm{Pb}^{2+}, \mathrm{Co}^{2+}$.

As the reactions list above, the hemicellulose based hydrogels were synthesized by grafting the acrylic acid to the backbone of the hemicellulose. The mechanism of the preparation of hydrogels briefly as follows: sulfate anion radical generated from ammonium persulfate deprives of hydrogen from the hydroxyl group of hemicellulose backbone to form alkoxy radicals, resulting in active centers on the hemicellulose to radically initiate polymerization (Peng et al., 2011; Sun et al., 2015). 


\subsection{Cross-Linking Agent Applied in Fabricating Hemicellulose Based Hydrogels}

The hemicelluloses usually react with acrylic acid through free radical polymerization of using N, N-methylene-bis-acrylamide (MBA) as cross-linker and ammonium persulfate $\mathrm{N}, \mathrm{N}, \mathrm{N}$ ', N'-tetramethylethylenediamine (APS/TMEDA) as Redox. The agent such as azo-bis-butyrnitrile (AIBN) (Cao, Peng, Zhong, \& Sun, 2014) and potassium persulfate (KPS) (Maleki, Edlund, \& Albertsson, 2015), sodium sulfite (Maleki et al., 2015), [2-(methacryloyloxy)ethyl] trimethylammonium chloride (MeDMA) (Dax et al., 2014) Sodium Pyrosulfite, ammonium persulfate (Ferrari, Ranucci, Edlund, \& Albertsson, 2014), N-N'-methylenebisacrylamide (Maleki, Edlund, \& Albertsson, 2016) as initiator, Also have prepared the hydrogel use freeze-thaw methods (Guan, Bian, Peng, Zhang, \& Sun, 2014; Guan, Zhang, Bian, Peng, \& Sun, 2014).

\subsection{Click Reaction of Hemicellulose and Thiol-Ene}

The click chemistry introduced by Sharpless, has attracted a lot of attention in many fields of chemistry. a click reaction should have these features such as highly efficient, no byproducts, be stereospecific, use readily available starting materials, use benign or no solvent, and require simple purification technique (Kolb, Finn, \& Sharpless, 2001). One of the most widely employed click reactions: thiol-ene has attracted attention in the last ten years due to the commercial availability of a wide range of thiols (Hoyle, Lowe, \& Bowman, 2010; Kade, Burke, \& Hawker, 2010). The versatility of thiol click reactions has been demonstrated by preparing tailor-made macromolecular architectures varying from telechelic homopolymers to highly complex dendritic structures (Jones et al., 2009; Nurmi, Lindqvist, Randev, Syrett, \& Haddleton, 2009).

AcGGM was materials for thiolation through one-pot synthetic methodology, this reaction realized by the AcGGM-mediated nucleophilic ring-opening reaction of thiobutyrolactone via the activation of the polysaccharide pendant hydroxyl groups. The first step is to synthesis thiolate acetyl galactoglucomannan, previous study was applied pendant amine or carboxylic acid via transesterfication to complete the objective products for several steps (Lin et al., 2010). However, in the reaction of thiol-ene click chemistry, it just needed one step. And the solvent used water as solvent, use thioacetic acid-ene approach; they successfully introduced thiol- amine- or amino acid functional xylan. First of all, the allyl chloride reacted with hydroxyl on xylan through esterification, secondly, via click chemistry; the thiol was introduced on the backbone of the xylan. The thiol-containing xylan was used to modify filter paper surface by a simple dipping method, which provides a novel and convenient (Pahimanolis, Kilpeläinen, Master, Ilvesniemi, \& Seppälä, 2015).

\subsection{Hemicellulose-Polymer Composite Hydrogels}

Hemicellulose based hydrogels attracted much attention and were focused on 
the free radical polymerization and click chemistry for fabrication of which has functional hydrogels. However, these hydrogels displayed many drawbacks such as weak thermostability, brittle properties and weak mechanical properties. To overcome these problems, plenty of methods were applied. Among of them, employing compatible ingredients such as nanowhiskers chitin, chitosan, polyvinyl alcohol, oat spelt and so, for enhancing their properties (Gabrielii \& Gatenholm, 2015; Guan, Bian, et al., 2014; Guan, Zhang, et al., 2014; Meena, Lehnen, Schmitt, \& Saake, 2011). Guan and coworkers (Guan, Zhang, et al., 2014) studied preparing hemicellulose based hydrogels through freeze-thaw treatment. In this study, the hydrogels were prepared from hemicelluloses, polyvinyl alcohol and nanowhiskers. With increasing the portion of chitin whiskers, the mechanical of the hydrogels were significantly improved, with the highest stress of 9.6 MPa. In another study (Gabrielii \& Gatenholm, 2015), the hydrogel complexing between glucuronic acid and amino acids indicated porous structure, sensitive to $\mathrm{pH}$.

IPNs are "alloys" of cross-linked polymers, at least one of them being synthesized and/or cross-linked within the immediate presence of the other, without any covalent bonds between them, which cannot be separated unless chemical bonds are broken (Dragan, 2014; Myung et al., 2008). IPN is a multi-component network made by molecular scale penetration of a linear or branched polymer into a cross-linked network that offer superior control and versatility over single network hydrogels with possibilities to tailor-make products with desired properties by mixing countless combinations of polymers with complementing characteristics (Matricardi et al., 2013; Myung et al., 2008; Reddy, Rao, Vani, Rao, \& Lee, 2016). In study by Malaki et al. employed the abundant hemicellulose by green method to fabricate the semi-IPN hydrogels. The hydrogel was directly produced by a facile and green synthetic pathway through cross-linking modified. A category of said composite networks can be developed by the simultaneous or sequential cross-linking of at least two polymer networks in juxtaposition. In another study of Maleki and coworkers (Maleki et al., 2017), AcGGM was employed to prepare IPNs-hydrogels via free radical polymerization and "click chemistry reaction" (Figure 5). As-prepared IPNs hydrogels indicated faster swelling rates, highly porous structure and significantly improved shear storage modulus than the corresponding precursor single networks of AcGGM (Maleki et al., 2017).

\subsection{Conductivity Hemicellulose Based Hydrogels}

Recent years, conducting polymers draw a lot of interest for provide more conductive environment and exhibiting improved impedance characteristics and provide a softer mechanical interface when compared to conventional metal electrodes (Green, Lovell, \& Poole-Warren, 2009). Recent studies have demonstrated that electrical stimuli can adjust a range of cellular activities, such as cell adhesion, migration, and proliferation (Yousaf, Houseman, \& Mrksich, 2001). There are many conduct polymers such as polyaniline and polypyrrole applied in biomaterial 

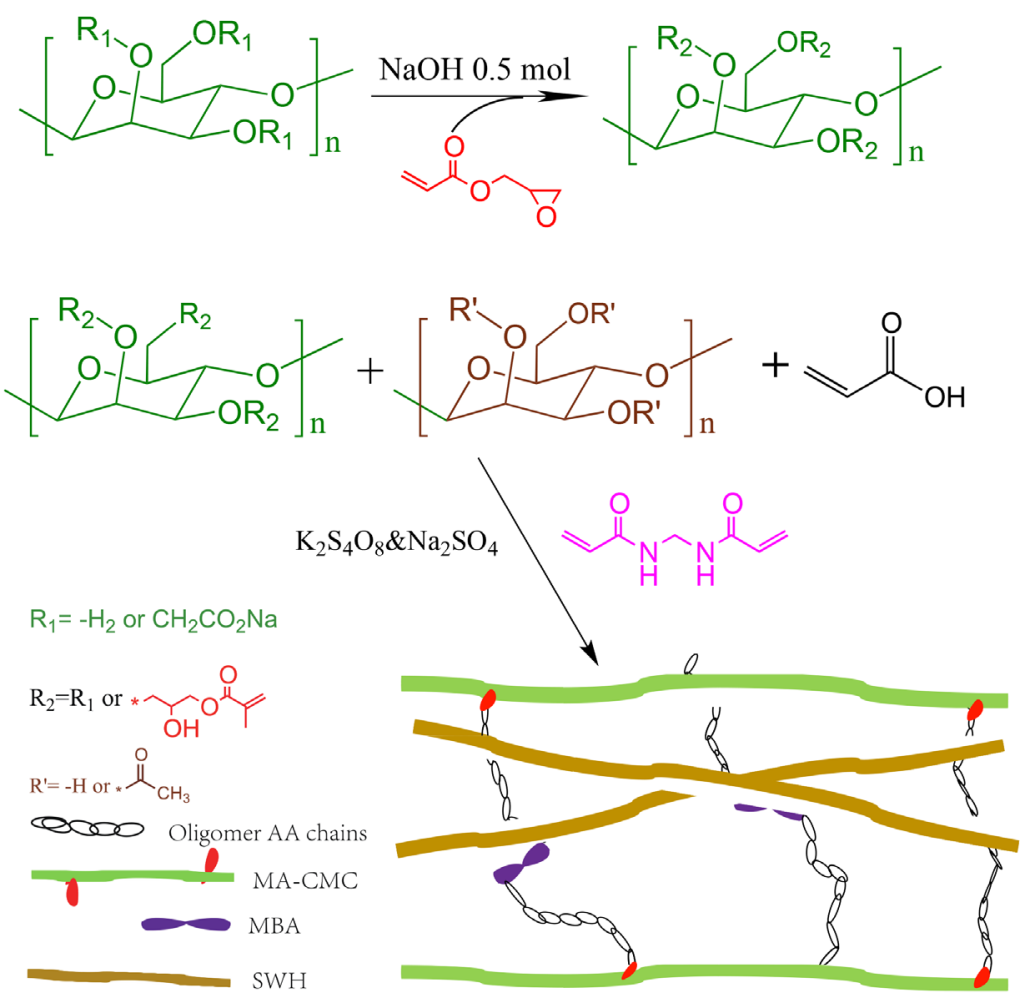

Figure 5. Synthetic pathway of preparing semi-IPN hydrogels (Maleki, Edlund, \& Albertsson, 2016).

field. However, they are not environmentally friend (Guo, Glavas, \& Albertsson, 2013). Zhao et al. synthesized electrically conductive hemicellulose hydrogels via one-pot reaction. In this study, o-acety-galactoglucomannan reacts with aniline pentamer. The reactions were green and ambient (water and room temperature). The author used aniline oligomers with carboxyl group to enhance the solubility in water, where previous studies that aniline with poor solubility in water (Meybodi, Imani, \& Atai, 2013). The hemicellulose based hydrogel were prepared through cross-linking reaction of AcGGM with epichlorohydrin in the presence of aniline pentama and sodium hydroxide (Figure 6).

The hydrogels without AP were transparent; however, due to dark of AP, ECHHs were opaque. And the FT-IR shows the structure of the ECHHs exist the carbonyl group and hemicellulose successfully incorporated to AP at $1568^{-1}$ peak. The smelling behavior affect a lot by cross-linker agent, and the thermal stability of ECHHs was enhanced, and the conductivity increased by 3 orders of magnitude.

\section{Applications of Hemicellulose Based Hydrogels}

Hemicellulose based hydrogels show high potential for utilization in remarkable applications. Unique properties, such as being branched polymers with several structures based on the different sources and the ability to be modified by several physical and chemical reactions, provides hemicellulose based hydrogel with an ability to be used in many fields. 


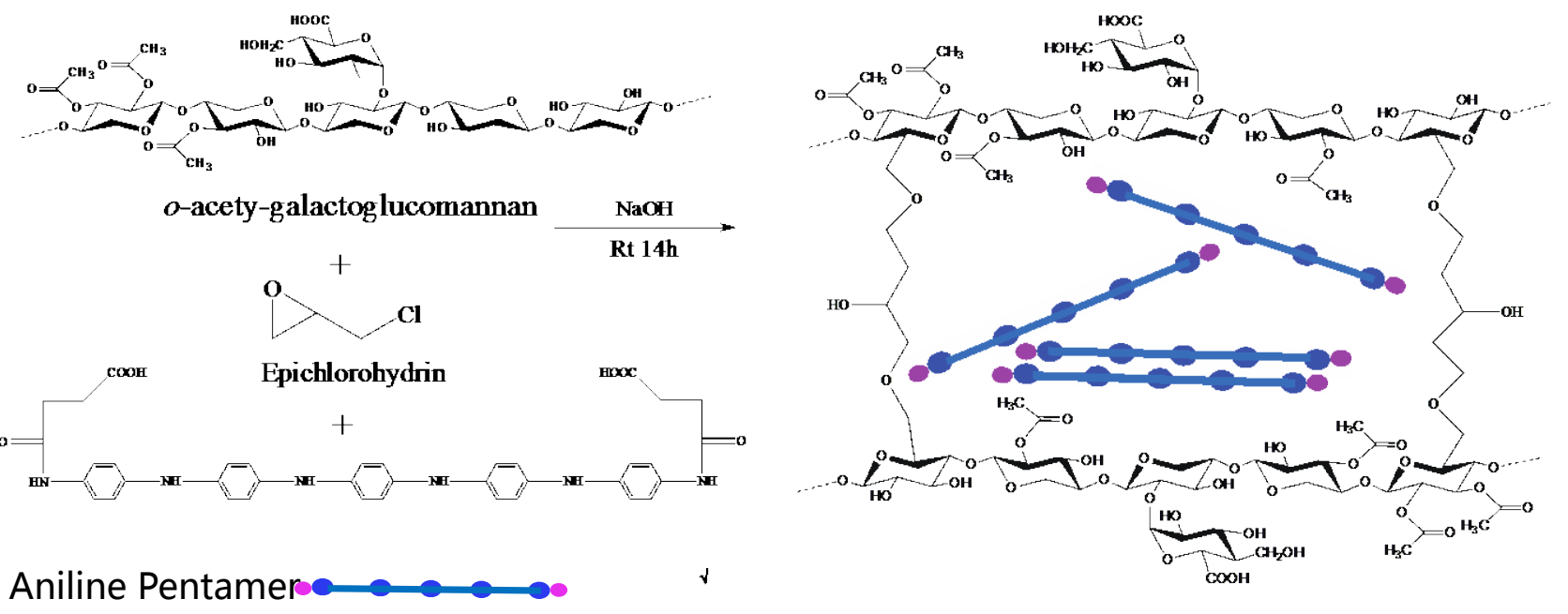

Figure 6. The synthetic pathway of conduct polymers (Zhao, Glavas, Odelius, Edlund, \& Albertsson, 2014).

Nowadays, as the development of economy and industrialization, environment was heavily polluted through water, atmosphere and soil. Among of them, the heavy metal pollution is harmful to human beings and animals, due to the heavy metal can penetrate in soil and water. Animals and mankind once take in the body; the heavy metal could accumulate in body hurt organs. In recent years, environmentally sensitive hydrogels have been widely applied as adsorbents for the removal of hazardous substances from waste water.

Sun and coworkers (Sun et al., 2015), using $\mathrm{CaCO}_{3}$ as the porogen, prepared the wheat straw hemicellulose based hydrogels, which had high adsorption capacity for methylene blue and smart swelling property. These properties were very significant for wastewater treatment application. In another research, macro porous xylan-rich hemicellulose based hydrogels were fabricated via free radical copolymerization of xylan and acrylic acid. In study, the results indicated that adsorption capacities of as-prepared hydrogels for up-taking $\mathrm{Pb}^{2+}, \mathrm{Cd}^{2+}$, and $\mathrm{Zn}^{2+}$ were $635,448,158 \mathrm{mg} / \mathrm{g}$ respectively. While, as the $\mathrm{pH}$ value increasing, due to the proton depriving by base, the adsorption capacity significantly increased. A novel hemicellulose based hydrogels were designed by Ferrari and coworkers (Ferrari et al., 2014). The amidoamine was introduced into the backbone of the hemicellulose, through water based free radical graft copolymerization and cross-linking. And the hydrogel displayed a significantly high adsorption capacity for $\mathrm{Cu}^{2+}, \mathrm{Cd}^{2+}, \mathrm{Pb}^{2+} \mathrm{Zn}^{2+}, \mathrm{Ni}^{2+}, \mathrm{Co}^{2+}$, and $\mathrm{CrO}_{4}^{2-}$.

\section{Summary and Overview}

The hemicelluloses based hydrogels as renewable and biodegradable materials, have a lot of favorable properties such as hydrophilicity, biodegradability, biocompatibility, transparency, low cost, and non-toxicity. Therefore, hemicellulose based hydrogel was widely applied in contact lenses, tissue engineering, and so on. Hemicellulose based hydrogels can be prepared via free radical pathway and click reaction of thiol directives. Theses hydrogels have been studied in drug de- 
livery, super adsorbent of heavy metal for environment treatment and adsorption of water. Recent researches into hemicellulose based hydrogels have combined hemicellulose with chitosan, polyvinyl alcohol to create hybrid hydrogels with anti-bacterial function.

However, hemicellulose based hydrogels are usually brittle and weak-strength, which restrict their application in material field. In future, preparing hemicellulose based hydrogels such as semi and full IPN hydrogels that have high strength and swelling capacity will have promising prospect. In addition, special functional hydrogels such as conductible, magnetic, and hybrid composites will attract lots of attention. In a word, hemicellulose is environmental friendly and low-cost hydrogels, which will form a viable substitute for fossil-based materials in near future.

\section{Acknowledgements}

This work was financial supported by the National Key R\&D Program of China (2016YFD0600803)

\section{References}

Ahmed, E. M. (2015). Hydrogel: Preparation, Characterization, and Applications: A Review. Journal of Advanced Research, 6, 105-121. https://doi.org/10.1016/j.jare.2013.07.006

Anwar, Z., Gulfraz, M., \& Irshad, M. (2014). Agro-Industrial Lignocellulosic Biomass a Key to Unlock the Future Bio-Energy: A Brief Review. Journal of Radiation Research and Applied Sciences, 7, 163-173. https://doi.org/10.1016/j.jrras.2014.02.003

Ayoub, A., Venditti, R. A., Pawlak, J. J., Sadeghifar, H., \& Salam, A. (2013). Development of an Acetylation Reaction of Switchgrass Hemicellulose in Ionic Liquid without Catalyst. Industrial Crops and Products, 44, 306-314. https://doi.org/10.1016/j.indcrop.2012.10.036

Beines, P. W., Klosterkamp, I., Menges, B., Jonas, U., \& Knoll, W. (2007). Responsive Thin Hydrogel Layers from Photo-Cross-Linkable Poly (N-isopropylacrylamide) Terpolymers. Langmuir, 23, 2231-2238. https://doi.org/10.1021/la063264t

Cao, X., Peng, X., Zhong, L., \& Sun, R. (2014). Multiresponsive Hydrogels Based on Xylan-Type Hemicelluloses and Photoisomerized Azobenzene Copolymer as Drug Delivery Carrier. Journal of Agricultural and Food Chemistry, 62, 10000-10007. https://doi.org/10.1021/jf504040s

Chang, C., Duan, B., \& Zhang, L. (2009). Fabrication and Characterization of Novel Macroporous Cellulose-Alginate Hydrogels. Polymer, 50, 5467-5473. https://doi.org/10.1016/j.polymer.2009.06.001

Chen, J., Jo, S., \& Park, K. (1995). Polysaccharide Hydrogels for Protein Drug Delivery. Carbohydrate Polymers, 28, 69-76. https://doi.org/10.1016/0144-8617(95)00080-1

Dax, D., Chávez, M. S., Xu, C., Willför, S., Mendonça, R. T., \& Sánchez, J. (2014). Cationic Hemicellulose-Based Hydrogels for Arsenic and Chromium Removal from Aqueous Solutions. Carbohydrate Polymers, 111, 797-805. https://doi.org/10.1016/j.carbpol.2014.05.045

De, R. V., \& Visser, J. (2001). Aspergillus Enzymes Involved in Degradation of Plant Cell Wall Polysaccharides. Microbiology and Molecular Biology Reviews: MMBR, 65, 497-522. https://doi.org/10.1128/MMBR.65.4.497-522.2001 
Dragan, E. S. (2014). Design and Applications of Interpenetrating Polymer Network Hydrogels. A Review. Chemical Engineering Journal, 243, 572-590. https://doi.org/10.1016/j.cej.2014.01.065

Egüés, I., Sanchez, C., Mondragon, I., \& Labidi, J. (2012). Effect of Alkaline and Autohydrolysis Processes on the Purity of Obtained Hemicelluloses from Corn Stalks. Bioresource Technology, 103, 239-248. https://doi.org/10.1016/j.biortech.2011.09.139

Ferrari, E., Ranucci, E., Edlund, U., \& Albertsson, A.-C. (2014). Design of Renewable Poly(Amidoamine)/Hemicellulose Hydrogels for Heavy Metal Adsorption. Journal of Applied Polymer Science, 132, 41695 p. https://doi.org/10.1002/app.41695

Ferreira, L. M., Blanes, L., Gragnani, A., Veiga, D. F., Veiga, F. P., Nery, G. B., \& Okamoto, R. (2009). Hemicellulose Dressing versus Rayon Dressing in the Re-Epithelialization of Split-Thickness Skin Graft Donor Sites: A Multicenter Study. Journal of Tissue Viability, 18, 88-94. https://doi.org/10.1016/j.jtv.2009.06.001

Froschauer, C., Hummel, M., Iakovlev, M., Roselli, A., Schottenberger, H., \& Sixta, H. (2013). Separation of Hemicellulose and Cellulose from Wood Pulp by Means of Ionic Liquid/Cosolvent Systems. Biomacromolecules, 14, 1741-1750. https://doi.org/10.1021/bm400106h

Gabrielii, I., \& Gatenholm, P. (2015). Preparation and Properties of Hydrogels Based on Hemicellulose. Journal of Applied Polymer Science, 69, 1661-1667. https://doi.org/10.1002/(SICI)1097-4628(19980822)69:8<1661::AID-APP19>3.0.CO;2-X

Green, R. A., Lovell, N. H., \& Poole-Warren, L. A. (2009). Cell Attachment Functionality of Bioactive Conducting Polymers for Neural Interfaces. Biomaterials, 30, 3637-3644. https://doi.org/10.1016/j.biomaterials.2009.03.043

Guan, Y., Bian, J., Peng, F., Zhang, X.-M., \& Sun, R.-C. (2014). High Strength of Hemicelluloses Based Hydrogels by Freeze/Thaw Technique. Carbohydrate Polymers, 101, 272-280. https://doi.org/10.1016/j.carbpol.2013.08.085

Guan, Y., Zhang, B., Bian, J., Peng, F., \& Sun, R.-C. (2014). Nanoreinforced Hemicellulose-Based Hydrogels Prepared by Freeze-Thaw Treatment. Cellulose, 21, 1709-1721. https://doi.org/10.1007/s10570-014-0211-9

Guo, B., Glavas, L., \& Albertsson, A.-C. (2013). Biodegradable and Electrically Conducting Polymers for Biomedical Applications. Progress in Polymer Science, 38, 1263-1286. https://doi.org/10.1016/j.progpolymsci.2013.06.003

Hasegawa, I., Tabata, K., Okuma, O., \& Mae, K. (2004). New Pretreatment Methods Combining a Hot Water Treatment and Water/Acetone Extraction for Thermo-Chemical Conversion of Biomass. Energy \& Fuels, 18, 755-760. https://doi.org/10.1021/ef030148e

Hennink, W. E., Franssen, O., van Dijk-Wolthuis, W. N. E., \& Talsma, H. (1997). Dextran Hydrogels for the Controlled Release of Proteins. Journal of Controlled Release, 48, 107-114. https://doi.org/10.1016/S0168-3659(97)00047-3

Hoyle, C. E., Lowe, A. B., \& Bowman, C. N. (2010). Thiol-Click Chemistry: A Multifaceted Toolbox for Small Molecule and Polymer Synthesis. Chemical Society Reviews, 39, 1355-1387. https://doi.org/10.1039/b901979k

Huang, J., Ten, E., Liu, G., Finzen, M., Yu, W., Lee, J. S., Tomsia, A. P. et al. (2013). Biocomposites of pHEMA with HA/ $\beta$-TCP (60/40) for Bone Tissue Engineering: Swelling, Hydrolytic Degradation, and in Vitro Behavior. Polymer, 54, 1197-1207. https://doi.org/10.1016/j.polymer.2012.12.045

Jagur-Grodzinski, J. (2009). Polymeric Gels and Hydrogels for Biomedical and Pharmaceutical Applications. Polymers for Advanced Technologies. https://doi.org/10.1002/pat.1504 
Jones, M. W., Mantovani, G., Ryan, S. M., Wang, X., Brayden, D. J., \& Haddleton, D. M. (2009). Phosphine-Mediated One-Pot Thiol-Ene "Click" Approach to Polymer-Protein Conjugates. Chemical Communications, 35, 5272-5274. https://doi.org/10.1039/b906865a

Kade, M. J., Burke, D. J., \& Hawker, C. J. (2010). The Power of Thiol-Ene Chemistry. Journal of Polymer Science Part A: Polymer Chemistry, 48, 743-750. https://doi.org/10.1002/pola.23824

Katsoulos, C., Karageorgiadis, L., Vasileiou, N., Mousafeiropoulos, T., \& Asimellis, G. (2009). Customized Hydrogel Contact Lenses for Keratoconus Incorporating Correction for Vertical Coma Aberration. Ophthalmic \& Physiological Optics: The Journal of the British College of Ophthalmic Opticians (Optometrists), 29, 321-329. https://doi.org/10.1111/j.1475-1313.2009.00645.x

Kolb, H. C., Finn, M. G., \& Sharpless, K. B. (2001). Click Chemistry: Diverse Chemical Function from a Few Good Reactions. Angewandte Chemie International Edition, 40, 2004-2021.

https://doi.org/10.1002/1521-3773(20010601)40:11<2004::AID-ANIE2004>3.0.CO;2-5

Lin, C., Zhao, P., Li, F., Guo, F., Li, Z., \& Wen, X. (2010). Thermosensitive in Situ Forming Dextran-Pluronic Hydrogels through Michael Addition. Materials Science and Engineering: $C$, 30, 1236-1244. https://doi.org/10.1016/j.msec.2010.07.004

Ma, Y., Tang, Y., Billingham, N. C., Armes, S. P., \& Lewis, A. L. (2003). Synthesis of Biocompatible, Stimuli-Responsive, Physical Gels Based on ABA Triblock Copolymers. Biomacromolecules, 4, 864-868. https://doi.org/10.1021/bm034118u

Maleki, L., Edlund, U., \& Albertsson, A.-C. (2015). Thiolated Hemicellulose as a Versatile Platform for One-Pot Click-Type Hydrogel Synthesis. Biomacromolecules, 16, 667-674. https://doi.org/10.1021/bm5018468

Maleki, L., Edlund, U., \& Albertsson, A.-C. (2016). Green Semi-IPN Hydrogels by Direct Utilization of Crude Wood Hydrolysates. ACS Sustainable Chemistry \& Engineering, 4, 4370-4377. https://doi.org/10.1021/acssuschemeng.6b00938

Maleki, L., Edlund, U., \& Albertsson, A.-C. (2017). Synthesis of Full Interpenetrating Hemicellulose Hydrogel Networks. Carbohydrate Polymers, 170, 254-263. https://doi.org/10.1016/j.carbpol.2017.04.091

Matricardi, P., Di Meo, C., Coviello, T., Hennink, W. E., \& Alhaique, F. (2013). Interpenetrating Polymer Networks Polysaccharide Hydrogels for Drug Delivery and Tissue Engineering. Advanced Drug Delivery Reviews, 65, 1172-1187. https://doi.org/10.1016/j.addr.2013.04.002

Meena, R., Lehnen, R., Schmitt, U., \& Saake, B. (2011). Effect of Oat Spelt and Beech Xylan on the Gelling Properties of Kappa-Carrageenan Hydrogels. Carbohydrate Polymers, 85, 529-540. https://doi.org/10.1016/j.carbpol.2011.03.002

Melandri, D., Angelis, A. D., Orioli, R., Ponzielli, G., Lualdi, P., Giarratana, N., \& Reiner, V. (2006). Use of a New Hemicellulose Dressing (Veloderm) for the Treatment of Split-Thickness Skin Graft Donor Sites: A Within-Patient Controlled Study. Burns, 32, 964-972. https://doi.org/10.1016/j.burns.2006.03.013

Meybodi, Z. E., Imani, M., \& Atai, M. (2013). Kinetics of Dextran Crosslinking by Epichlorohydrin: A Rheometry and Equilibrium Swelling Study. Carbohydrate Polymers, 92, 1792-1798. https://doi.org/10.1016/j.carbpol.2012.11.030

Myung, D., Waters, D., Wiseman, M., Duhamel, P. E., Noolandi, J., Ta, C. N., \& Frank, C. W. (2008). Progress in the Development of Interpenetrating Polymer Network Hydrogels. Polymers for Advanced Technologies, 19, 647-657. https://doi.org/10.1002/pat.1134 
Nguyen, Q. A., Tucker, M. P., Keller, F. A., \& Eddy, F. P. (2000). Two-Stage Dilute-Acid Pretreatment of Softwoods. Applied Biochemistry and Biotechnology, 84-86, 561-576. https://doi.org/10.1385/ABAB:84-86:1-9:561

Noro, A., Hayashi, M., \& Matsushita, Y. (2012). Design and Properties of Supramolecular Polymer Gels. Soft Matter, 8, 6416-6429. https://doi.org/10.1039/c2sm25144b

Nurmi, L., Lindqvist, J., Randev, R., Syrett, J., \& Haddleton, D. M. (2009). Glycopolymers via Catalytic Chain Transfer Polymerisation (CCTP), Huisgens Cycloaddition and Thiol-Ene Double Click Reactions. Chemical Communications (Cambridge, England), No. 19, 2727-2729. https://doi.org/10.1039/b904249k

Pahimanolis, N., Kilpeläinen, P., Master, E., Ilvesniemi, H., \& Seppälä, J. (2015). Novel Thiol-Amine and Amino Acid Functional Xylan Derivatives Synthesized by Thiol-Ene Reaction. Carbohydrate Polymers, 131, 392-398. https://doi.org/10.1016/j.carbpol.2015.06.007

Palm, M., \& Zacchi, G. (2003). Extraction of Hemicellulosic Oligosaccharides from Spruce using Microwave Oven or Steam Treatment. Biomacromolecules, 4, 617-623. https://doi.org/10.1021/bm020112d

Peng, X.-W., Ren, J.-L., Zhong, L.-X., Peng, F., \& Sun, R.-C. (2011). Xylan-Rich Hemicelluloses-Graft-Acrylic Acid Ionic Hydrogels with Rapid Responses to $\mathrm{pH}$, Salt, and Organic Solvents. Journal of Agricultural and Food Chemistry, 59, 8208-8215. https://doi.org/10.1021/jf201589y

Reddy, N. S., Rao, K. M., Vani, T. J. S., Rao, K. S. V. K., \& Lee, Y. I. (2016). Pectin/poly(acrylamide-co-acrylamidoglycolic acid) $\mathrm{pH}$ Sensitive Semi-IPN Hydrogels: Selective Removal of $\mathrm{Cu} 2+$ and $\mathrm{Ni} 2+$, Modeling, and Kinetic Studies. Desalination and Water Treatment, 57, 6503-6514. https://doi.org/10.1080/19443994.2015.1008053

Seliktar, D. (2012). Designing Cell-Compatible Hydrogels for Biomedical Applications. Science, 336, 1124-1128. https://doi.org/10.1126/science.1214804

Sun, X.-F., Gan, Z., Jing, Z., Wang, H., Wang, D., \& Jin, Y. (2015). Adsorption of Methylene Blue on Hemicellulose-Based Stimuli-Responsive Porous Hydrogel. Journal of Applied Polymer Science, 132. https://doi.org/10.1002/app.41606

Sun, X.-F., Wang, H., Jing, Z., \& Mohanathas, R. (2013). Hemicellulose-Based $\mathrm{pH}$-Sensitive and Biodegradable Hydrogel for Controlled Drug Delivery. Carbohydrate Polymers, 92, 1357-1366. https://doi.org/10.1016/j.carbpol.2012.10.032

Van Tuil, R., Fowler, P., Lawther, M., \& Weber, C. J. (2000). Biobased Packaging Materials for the Food Industry. Journal of Food Science and Technology, 5.

Voepel, J., Sjöberg, J., Reif, M., Albertsson, A.-C., Hultin, U.-K., \& Gasslander, U. (2009). Drug Diffusion in Neutral and Ionic Hydrogels Assembled from Acetylated Galactoglucomannan. Journal of Applied Polymer Science, 112, 2401-2412. https://doi.org/10.1002/app.29878

Yamato, M., Konno, C., Utsumi, M., Kikuchi, A., \& Okano, T. (2002). Thermally Responsive Polymer-Grafted Surfaces Facilitate Patterned Cell Seeding and Co-Culture. Biomaterials, 23, 561. https://doi.org/10.1016/S0142-9612(01)00138-7

Yasuda, H. (2006). Biocompatibility of Nanofilm-Encapsulated Silicone and Silicone-Hydrogel Contact Lenses. Macromolecular Bioscience, 6, 121-138. https://doi.org/10.1002/mabi.200500153

Yousaf, M. N., Houseman, B. T., \& Mrksich, M. (2001). Turning on Cell Migration with Electroactive Substrates. Angewandte Chemie International Edition, 40, 1093-1096. https://doi.org/10.1002/1521-3773(20010316)40:6<1093::AID-ANIE10930>3.0.CO;2-Q

Zhang, H., Mardyani, S., Chan, W. C. W., \& Kumacheva, E. (2006). Design of Biocom- 
patible Chitosan Microgels for Targeted pH-Mediated Intracellular Release of Cancer Therapeutics. Biomacromolecules, 7, 1568-1572. https://doi.org/10.1021/bm050912z

Zhao, W., Glavas, L., Odelius, K., Edlund, U., \& Albertsson, A. C. (2014). Facile and Green Approach towards Electrically Conductive Hemicellulose Hydrogels with Tunable Conductivity and Swelling Behavior. Chemistry of Materials, 26, 4265-4273.

https://doi.org/10.1021/cm501852w 